\title{
Koolijuhtide valmisolek kaasata üldhariduskoolide ettevõtlusõppesse kooliväliseid huvirühmi
}

\author{
Minna Hämäläinen ${ }^{a 1}$, Elena Ruskovaara ${ }^{a}$, Timo Pihkala ${ }^{a}$ \\ ${ }^{a}$ Lappeenranta Tehnoloogiaülikool
}

\begin{abstract}
Annotatsioon
Artikli eesmärk on uurida koolijuhtide tegevust ettevõtlusõpet toetavate võrgustike arendamisel. Uurimuses keskendume sellele osale koolijuhtide tegevusest, mis on seotud ettevõtlusõppe arendamisega koolides. Täpsemalt öeldes vaatleme, kuidas kaasavad koolijuhid väliseid huvirühmi koolide tegevusse. Uurimuse ajendiks sai asjaolu, et kuigi ettevõtlusõpet toetavad välised huvirühmad on olemas, ei kasuta koolijuhid ja koolid pakutavaid võimalusi täiel määral ära. Meie arvates võib kooliväliste huvirühmade kaasamine sõltuda koolijuhtide isikuomadustest, mistõttu uurime, kas ja kuidas mõjutab koolijuhtide taust kooliväliste huvirühmade kaasamist. Sellele lisaks proovime selgusele jõuda, kuidas mõjutab koolijuhtide osalemine ettevõtlusõppekoolitusel kooliväliste huvirühmade kaasamist. Uurimismeetodina kasutame dispersioonanalüüsi ja lineaarset regressioonanalüüsi. Valim koosneb 173 Soome üldhariduskooli ${ }^{2}$ koolijuhist. Artikliga täiendame ettevõtlusõppele pühendatud teaduskirjandust, analüüsides ettevõtlusõpet toetavaid kooliväliseid huvirühmi. Keskendume eeskätt koolijuhi rollile selles protsessis. Artikkel pakub empiirilisi tõendeid selle kohta, kuivõrd olulist osa täidab koolijuhtide koolitamine väliste huvirühmade kaasamisel ettevõtlusõppesse.
\end{abstract}

Võtmesõnad: ettevõtlusõpe, koolijuht, koolivälised huvirühmad, arenevad koolid

\section{Sissejuhatus}

Ettevõtlusõpe on Euroopa haridussüsteemis kindlalt kanda kinnitanud. Euroopa Liidu tegevuskavas „Ettevõtlus 2020“ (European Commission, 2013)

School of Business and Management, Lappeenranta University of Technology (LUT), P.O. Box 20, FI-53851 Lappeenranta, Soome; Minna.Hamalainen@lut.fi

2 Soomes omandatakse üldharidus tavaliselt 7. ja 18. eluaasta vahel ning see hõlmab haridust alates algkoolist kuni keskkooli teise astme lõpuni. 
kirjeldatakse ettevõtlust kui oskust, mida on võimalik õppida, ning rõhutatakse ettevõtliku mõtteviisi ja ettevõtlusoskuste olulisust. Eesmärk on kasvatada ettevõtlikke, vastutustundlikke ja sihikindlaid inimesi, kellel on olemas ettevõtluseks vajalikud oskused, teadmised ja hoiakud. Enamgi veel, ettevõtlikkust peetakse Euroopa kodanike üheks võtmepädevuseks (European Parliament and the Council, 2006). Ettevõtlushariduse tähtsust Euroopa jaoks kinnitab asjaolu, et ettevõtlikud inimesed saavad kergemini tööd ja ettevõtlusõpe mõjub noortele selliselt, et neist saavad tõenäolisemalt uute ettevõtete asutajad (European Commission, 2013).

Ettevõtlusõpet toetatakse ja suunatakse mitmel viisil ning hiljutise Eurydice (2016) aruande kohaselt on 11 Euroopa riiki või piirkonda välja töötanud üksikasjaliku ettevõtlusõppe strateegia koolidele. Soome on olnud selles protsessis juhtival kohal ja alates 1994. aastast on ettevõtlusõpe kuulunud Soome riiklikusse põhiõppekavasse (Ministry of Education, 2009). Hoolimata eespool nimetatud dokumentidest ja strateegiatest tundub ometi, et koostöö väliste huvirühmadega ei ole siiski piisavalt tõhus.

Koolijuhtide ja ettevõtlusõppe vahelisi seoseid on vähe uuritud (Birdthistle, Hynes, \& Fleming, 2007; Ememe, Ezeh, \& Ekemezie, 2013; Hämäläinen, Ruskovaara, \& Pihkala, 2018; Ruskovaara, Hämäläinen, \& Pihkala, 2016). Lisaks on veidi uuritud võimalusi, kuidas välised huvirühmad saaksid laiendada ettevõtlusõppega seotud tegevust koolides (Deakins, Glancey, Menter, \& Wyper, 2005; Jones \& Iredale, 2010; Matlay, 2009). Nende uurimuste põhjal võib väita, et nii koolijuhtidel kui ka välistel huvirühmadel näib olevat ülioluline roll koolide ettevõtlusõppes, kuid meil ei õnnestunud leida ühtegi uurimust, kus oleks vaadeldud koolijuhte ja kooliväliseid huvirühmi koos. Selle tühimiku täitmiseks proovime siinkohal välja selgitada, kuidas kasutavad koolijuhid väliseid huvirühmi koolide ja neis rakendatava ettevõtlusõppe arendamiseks. Uurimuses küsime: „Kuidas kaasavad koolijuhid väliseid huvirühmi oma kooli ettevõtlusõppesse?“

Varasemad uurimused (Bennett, 2006; Gibb, 2011) on näidanud, et ettevõtluskogemustel on ettevõtlusõppele positiivne mõju. Seetõttu keskendusime just koolijuhtide tausta uurimisele, samuti vaatasime, kas ja kuidas mõjutab koolijuhi taust väliste huvirühmade kasutamist koolis. Sellise uurimisküsimuse valikuga seame fookusse koolijuhi töökorraldusliku tegevuse. Eeldame, et kooli igapäevase tegevuse juhina on koolijuhil määrav roll kooliväliste suhete üle otsustamisel (Deakins et al., 2005; Ememe et al., 2013; Hämäläinen et al., 2018; Ruskovaara et al., 2016).

Kuna varem ei ole seda teemat sarnasel viisil uuritud, siis pidime oma väited kombineerima suhteliselt erinevaid aspekte käsitlevate uurimuste põhjal. Kasutame eelkõige selliseid uurimusi, milles vaadeldakse õpetajaid ja nende tegevust 
ettevõtluse õpetamisel. Seega toetume uurimustele, milles käsitletakse õpetajate koostööd väliste huvirühmadega.

Siinne uurimus pakub ettevõtlusõppe kohta käivale teaduskirjandusele täiendust kahel viisil: analüüsime väliste huvirühmade kaasamist ettevõtlusõppesse ning kujundame uue arusaama koolijuhi rollist ja eelkõige tema tausta olulisusest selles protsessis.

\section{Huvirühmade kaasamine ettevõtlusõppesse}

Uurimused on näidanud, et väliste ressursside kasutamine mõjutab otseselt koolide ettevõtlusõppe taset (Deakins et al., 2005; Jones \& Iredale, 2010). Matlay (2009) leiab, et väliste huvirühmade kaasamine ettevõtlusõppesse rikastab ja mõjutab pidevalt arendatavat haridussüsteemi. Pealegi juhivad Pittaway ja Hannon (2008) tähelepanu sellele, et suhete arendamine väliste huvirühmadega on koolile strateegilise tähtsusega küsimus ning et koolivälised huvirühmad täidavad ülitähtsat osa ettevõtlusõppe arendamisel haridusasutustes. Seejuures võib kirjandusest (Dickson, Solomon, \& Weaver, 2008; Jones \& Iredale, 2010) leida mõningaid näpunäiteid väliste huvirühmade kaasamiseks ettevõtlusõppesse. Esiteks pakuvad pea kõik huvirühmad õpetajatele kasutamiseks asjakohaseid sisumaterjale ja kogemusõppe mudeleid. Seega ei võtaks huvirühmad otseselt üle õpetamist, vaid looksid õpetaja jaoks tugisüsteemi. Teiseks saaksid mõned huvirühmad ühiste tegevuste kaudu pakkuda õpetajatele ja õpilastele isiklikel kogemustel ja katsetel põhinevaid teadmisi ning aidata mõista väljaspool kooli eksisteerivaid kirjutamata seadusi. Lisaks võivad välised huvirühmad investeerida aega ja raha ettevõtlusõppega seotud tegevustesse koolis. See võib toimuda eriprojektide, teemapäevade, ettevõtete külastamise ja loengutes osalemise kaudu (Bell, Callaghan, Demick, \& Scharf, 2004; Birdthistle et al., 2007; Cooper, Bottomley, \& Gordon, 2004; Dickson et al., 2008; Gibb, 2011; Sommarström, Ruskovaara, \& Pihkala, 2017).

Koolijuhi ja kooli seisukohalt on kohalikud ettevõtjad ja mittetulundusühendused osa ülivajalikust ettevõtlusõppe võrgustikust. Sellistesse võrgustikesse võivad kuuluda ettevõtted ja nende liidud, kuid ka riiklikud ja rahvusvahelised organisatsioonid või ühendused ning projektid. Uurimused on näidanud, et nende ressursside kasutamine mõjutab otseselt koolide ettevõtlusõppe taset (Deakins et al., 2005; Jones \& Iredale, 2010).

Koolijuhid koolide pedagoogiliste ja administratiivjuhtidena mõjutavad kooli tegevust mitmel viisil (Hämäläinen et al., 2018). Seetõttu on koolijuhtide juhtimisvõimet ja kooli korraldust põhjalikult uuritud. Olgugi et Ballou ja Podgursky (1995) ei leidnud positiivset seost koolijuhtide ettevõtlusalase töökogemuse ja nende juhtimistegevuse tulemuslikkuse vahel, on teised uuri- 
mused näidanud, et reaalelus ettevõtjana tegutsemise kogemus arendab ettevõtluse õpetajana tegutsemise pädevust (Gibb, 2011; Ruskovaara, Pihkala, Seikkula-Leino, \& Järvinen, 2015a). Peale selle leiab Bennett (2006), et ettevõtetes saadaval töökogemusel ja ettevõtjana tegutsemisel on positiivne mõju sellele, kuidas pedagoogid rakendavad ettevõtlusõpet. Varasemat ettevõtluskogemust, nt loodud ärikontakte ja -võrgustikke, ärikeele tundmist ja omandatud käitumismustreid, mis lihtsustavad ettevõtjatega suhtlemist, samuti ettevõtete ootuste mõistmist seoses vastastikku kasulike suhetega ja seeläbi huvirühmade koostööhuvi suurendamist, võiks vaadelda kui sotsiaalset kapitali, mis loob paremad võimalused koostööks. Samas leiab Seikkula-Leino (2007), et ettevõtlusalase tööstaaži pikkus ei mõjuta õpetaja ettevõtlusõpet. Näib, et isegi vähesed kättesaadavad uurimused koolijuhtide ja ettevõtlusõppe seoste kohta on üksteisega teatud määral vastuolus. Samas näivad uurijad siiski olevat ühel nõul, et ettevõtlusega seotud koolitus mõjutab positiivselt õpetajate ja koolijuhtide ettevõtlusõppealast tegevust (Bennett, 2006; Deakins et al., 2005; Ruskovaara et al., 2016).

Siinses artiklis on uurimiseks esitatud järgmised väited:

1. väide: mida suurem on koolijuhi ettevõtluskogemus, seda altim on ta kaasama väliseid huvirühmi ettevõtlusõppesse (Bennett, 2006; Gibb, 2011; Ruskovaara \& Pihkala, 2015; Sullivan, 2000);

2. väide: koolijuhi staažil ei ole mingit mõju väliste huvirühmade kaasamisele ettevõtlusõppesse (Ruskovaara \& Pihkala, 2015; Ruskovaara et al., 2016; Seikkula-Leino, 2007);

3. väide: ettevõtlusega seotud koolitusel osalemine mõjutab koolijuhti väliseid huvirühmi ettevõtlusõppesse rohkem kaasama (Bennett, 2006; Ruskovaara \& Pihkala, 2013; Ruskovaara et al., 2015a; Ruskovaara et al., 2016).

\section{Meetodid}

Andmeid koguti ettevõtlusõppe mõõdikuga (Measurement Tool for Enterprise Education, MTEE) Soomes. Mõõdik loodi koostöös riikliku haridusametiga ning paljude alg- ja keskastmehariduse õpetajate ja koolijuhtidega. Mõõdiku usaldusväärsus ja täpsus on tagatud testimise ning kordustestimise kaudu (Ruskovaara, Pihkala, Seikkula-Leino, \& Rytkölä, 2015b). Mõõdik on kogu skaalat hõlmav veebiküsimustik, mille abil määratakse kindlaks õpetajate ja koolijuhtide tegevused seoses ettevõtlusõppega (ibid.). Vastajad kasutavad mõõdikut vabatahtlikult ja andmete töötlemisel tagatakse vastajate anonüümsus.

Analüüsi tarbeks määrasime kindlaks kümme koolivälist huvirühma, kes osalevad ettevõtlusõppes. Valikukriteeriumid olid järgmised: 1) organisatsioon 
peab ettevõtlusõppe arendamises aktiivselt osalema; 2) organisatsioon pakub õpetajatele või koolijuhtidele toetust, õppematerjale ja/või koolitusi; 3) organisatsioon tegutseb tasuta; 4) organisatsiooniga on võimalik kontakti saada kõikides Soome piirkondades ja suurem osa selle materjalidest on kättesaadav internetis; 5) organisatsioon on ettevõtluses tegutsenud vähemalt kümme aastat.

Analüüsi lisasime neli tunnusjoont, mis iseloomustavad koolijuhi tausta (vt nende kriteeriumite kirjeldavat statistikat tabelist 1). Koolijuhtide omadused pidid vastama järgmistele kriteeriumitele: 1) sugu - dihhotoomne indikaator vastaja soo määramiseks: mehe puhul kodeeriti indikaator andmetes 0 -ga, naise puhul 1-ga; 2) ettevõtlustaust - dihhotoomne indikaator selle kohta, kas koolijuhil on ettevõtluskogemus: kogemuse puudumine kodeeriti 0-ga, kogemuse olemasolu 1-ga; 3) töökogemus - skaalal kas 0-10 aastat, 11-20 aastat, 21-30 aastat või rohkem kui 30 aastat (kogemuse tunnus viitab sellele, mitu aastat on koolijuht oma ametikohal töötanud); 4) ettevõtlusõpet käsitlevate kursuste või koolituspäevade arv - arvuline näitaja, mis kajastab mis tahes liiki või kestusega ettevõtlusõppe kursusi või koolituspäevi (teoreetilisi või praktilisi koolitusi), millel koolijuht on osalenud. Andmed esitatakse järgmisel skaalal: ,ei ole osalenud“ $=0$, „osalenud mõnel koolitusel“ $=1$, ,osalenud paljudel koolitustel“ $^{\text {“ }}=2$. Analüüsi kontrolltunnustena lisasime soo ja kooli suuruse.

Tabel 1 kirjeldab vastajate profiili. Kumbki sugu on esindatud peaaegu võrdselt. Suuremal osal koolijuhtidest on enam kui 20 aastat töökogemust. Olgugi et üllatavalt suur osa koolijuhtidest on ettevõtlustaustaga, esindab vastajate profiil Soome koolijuhte üsna täpselt (vt Opetushallitus, 2017).

Tabel 1. Vastajate kirjeldus $(n=173)$

\begin{tabular}{lccc}
\hline & & Arv & $\%$ \\
\hline Sugu & Mehed & 90 & 52 \\
\hline Ettevõtlustaust & Naised & 83 & 48 \\
\hline & Ei & 93 & 53,8 \\
\hline Töökogemus & Jah & 80 & 46,2 \\
\hline & $0-10$ aastat & 18 & 10,4 \\
\hline & $11-20$ aastat & 61 & 35,3 \\
\hline Osalemine ettevõtluskoolitusel & $21-30$ aastat & 70 & 40,5 \\
\hline & Üle 31 aasta & 24 & 13,9 \\
\hline & Ei & 63 & 36,4 \\
\hline & Mõnel & 93 & 53,8 \\
\hline
\end{tabular}




\begin{tabular}{lccc}
\hline & & Arv & $\%$ \\
\hline Kooli suurus & Kuni 100 õpilast & 45 & 26,0 \\
\hline & $100-299$ õpilast & 65 & 34,6 \\
\hline $300-499$ õpilast & 321 & 18,5 \\
\hline Üle 500 õpilase & 31 & 17,9 \\
\hline
\end{tabular}

\section{Tulemused}

Analüüsis keskendume kümnele Soomes tegutsevale välisele huvirühmale, keda koolijuhid õppetöösse kaasasid (tabel 2). Sel otstarbel sisaldas küsimustik küsimust „Kas olete viimase kuue kuu jooksul kaasanud järgmisi kooliväliseid huvirühmi õppetöösse?” (jah/ei). Tabelis 2 on esitatud kõikide partnerite kaasamise osakaal. Majandusteabebüroo näib olevat kõige enam kaasatud partner, samas kui vaid üksikud koolijuhid on teinud koostööd INNOSUOMIga: peaaegu pooled koolijuhtidest $(48,6 \%)$ on kasutanud majandusteabebüroo teenuseid, samas vaid $12,7 \%$ on kasutanud INNOSUOMI omi. Ka Soome 4-H organisatsioon $(43,4 \%)$ on valdkonnas hästi kanda kinnitanud, samuti tööhõive ja majanduse arengu büroo (39,3\%). 15-20\% koolijuhtidest märkis, et on kasutanud kohaliku omavalitsuse või ülikoolide teenuseid. Piirkondlik ettevõtlusõppekeskus YES (36,4\%) ja Junior Achievement Finland $(28,3 \%)$ on organisatsioonid, mis on fookustatud eelkõige ettevõtlusõppele, samas kui teised organisatsioonid pakuvad koolidele toetust ka muudes valdkondades.

Tabel 2. Huvirühmade kaasamise osakaal koolijuhtide hulgas $(n=173)$

\begin{tabular}{lc}
\hline & $\begin{array}{c}\text { Kasutusprotsent } \\
\text { koolijuhtide hulgas }\end{array}$ \\
\hline Majandusteabebüroo & $48,6 \%$ \\
\hline Soome 4-H & $43,4 \%$ \\
\hline Tööhõive ja majanduse arengu büroo & $39,3 \%$ \\
\hline Piirkondlik ettevõtlusõppekeskus YES & $36,4 \%$ \\
\hline Arenduskeskus Opinkirjo & $32,9 \%$ \\
\hline Junior Achievement Finland & $28,3 \%$ \\
\hline Soome Ettevõtete Liit & $24,3 \%$ \\
\hline Kohalike omavalitsuste ettevõtlusteenused & $17,3 \%$ \\
\hline Ülikooli ettevõtlusüksus & $16,2 \%$ \\
\hline Innovatsiooni edendamise organisatsioon INNOSUOMI & $12,7 \%$ \\
\hline
\end{tabular}


Väliste huvirühmade kaasamise sageduse alusel koostasime uue koondmuutuja nimetusega „huvirühmad“, et kirjeldada koolijuhtide koostöövalmidust. Väliste huvirühmade kaasamise sageduse põhjal jäid koolijuhtide profiilid vahemikku 0-10 (keskmine oli 2,99), mediaan ulatus 3,00-ni ja mood oli 1,00. See näitas, et tüüpiline koolijuht kasutab üht eespool nimetatud partneritest, kuid on ka aktiivsemaid koolijuhte ja seetõttu jääb keskmine kolme juurde.

Tabel 3 annab hea ülevaate väliste huvirühmade kaasamisest koolijuhtide seas. Esiteks ei sõltu väliste huvirühmade kaasamine koolijuhi soost. Teiseks tekitasid koolijuhi ettevõtlustaust ja töökogemus koolijuhina märkimisväärseid erinevusi huvirühmade kaasamises, mis tähendab, et koolijuhi staaž tingib erinevused huvirühmade kaasamise sageduses ja et kõige aktiivsemad on koolijuhid, kellel on 21-30 aastat töökogemust. Mis puudutab koolijuhtide ettevõtlustausta, siis ettevõtluskogemusega koolijuhid tundusid olevat aktiivsemad suhete arendamisel väliste huvirühmadega. Huvitaval kombel olid suuremate koolide näitajad kõrgemad, kuid koolide suurus ei tekitanud märkimisväärseid erinevusi. Lõpetuseks, mida rohkem olid koolijuhid saanud ettevõtlusõppe koolitusi, seda rohkem kaasasid nad väliseid huvirühmi tegevusse.

Tabel 3. Väliste huvirühmade kaasamise seos koolijuhi tausta ja koolitustes osalemisega

\begin{tabular}{|c|c|c|c|c|}
\hline & Muutuja & Keskväärtus & $F$ & $p$ \\
\hline \multirow[t]{2}{*}{ Sugu } & Mees & 2,97 & 0,028 & 0,868 \\
\hline & Naine & 3,02 & & \\
\hline \multirow[t]{2}{*}{ Ettevõtlustaust } & $\mathrm{Ei}$ & 2,60 & $6,233^{*}$ & 0,013 \\
\hline & Jah & 3,45 & & \\
\hline \multirow[t]{4}{*}{ Töökogemus } & $0-10$ aastat & 1,39 & $4,124^{* *}$ & 0,007 \\
\hline & $11-20$ aastat & 3,02 & & \\
\hline & $21-30$ aastat & 3,43 & & \\
\hline & Üle 31 aasta & 2,88 & & \\
\hline \multirow{3}{*}{$\begin{array}{l}\text { Osalemine ettevõtlusõppe kooli- } \\
\text { tusel }\end{array}$} & $\mathrm{Ei}$ & 1,87 & $23,116^{* * *}$ & 0,000 \\
\hline & Mõnel & 3,31 & & \\
\hline & Paljudel & 5,41 & & \\
\hline \multirow[t]{4}{*}{ Kooli suurus } & Kuni 100 õpilast & 2,36 & 2,37 & 0,073 \\
\hline & 100-299 õpilast & 3,00 & & \\
\hline & 300-499 õpilast & 3,19 & & \\
\hline & Üle 500 õpilase & 3,71 & & \\
\hline
\end{tabular}

Märkus. ${ }^{*}-p<0,05 ;{ }^{* *}-p<0,01 ;{ }^{* * *}-p<0,001$. 
Järgmisena analüüsisime koolijuhtide tausta seost väliste huvirühmade kaasamisega. Lineaarne regressioonanalüüs (tabel 4) näitab, et determinatsioonikordaja tase on mõõdukas ehk 0,274. Märkimisväärsed beetakordajad avalduvad vaid seoses ettevõtlusõppe kursustel osalemise ja kooli suurusega. Hoolimata statistiliselt olulistest rühmatasandi erinevustest koolijuhtide ettevõtlustaustas ja töökogemuses, näib siiski, et neist ei piisa, seletamaks väliste huvirühmade kaasamist koolijuhtide seas. Huvitaval kombel on kooli suurus oluline, sest mida suurem on kool, seda enam kaasavad nende juhid väliseid huvirühmi.

Tabel 4. Huvirühmade kaasamise regressioonanalüüs

\begin{tabular}{ll}
\hline Tunnus & Mudel 1 \\
\hline Konstant & $-0,412$ \\
\hline Sugu & 0,525 \\
\hline Ettevõtlustaust & 0,364 \\
\hline Töökogemus & 0,341 \\
\hline Osalemine ettevõtlusõppe koolitusel & $1,565^{* * *}$ \\
\hline Kooli suurus & $0,420^{* *}$ \\
\hline Determinatsioonikordaja & $0,274^{* * *}$ \\
\hline
\end{tabular}

Märkus. ${ }^{*}-p<0,05 ;^{* *}-p<0,01 ;{ }^{* *}-p<0,001$.

\section{Kokkuvõte}

Oma esimeses väites eeldasime, et „mida suurem on koolijuhi ettevõtluskogemus, seda altim on ta kaasama väliseid huvirühmi ettevõtlusõppesse“. Analüüs näitab, et koolijuhtide ettevõtlustaust ei aita kaasa väliste huvirühmade kaasamisele. Seega ei leidnud esimene väide kinnitust. Varasemate uurimustega võrreldes on selline tulemus veidi üllatav. Kuigi Bennett (2006) märgib, et pikaajaline praktiline kogemus mõjutab positiivselt ettevõtlusele orienteeritud tegevuse omaksvõtmist, viitavad meie andmed siiski sellele, et ettevõtluskogemusel ei ole väliste huvirühmade kaasamisele mingit mõju. Seega ei sõltu koostöövõrgustike arendamine koolijuhtide varem kogutud sotsiaalsest kapitalist, vaid mõnest muust tegurist. Näiteks võidakse koostöövõrgustikke arendada hoopis huvirühmade initsiatiivil, olles mõjutatud soovist alustada koostööd koolidega, hoolimata sellega kaasnevatest raskustest.

Teine väide „koolijuhi staažil ei ole mingit mõju väliste huvirühmade kaasamisele ettevõtlusõppesse“ ei leidnud samuti kinnitust. Seega näib koolijuhi 
töökogemus olevat määrava tähtsusega, samuti ilmnevad erinevused vähese staažiga ja kogenud koolijuhtide vahel. Huvitaval kombel näitab statistika kõverjoonena kulgemise tendentsi ehk kõige lühema töökogemusega koolijuhid on kõige vähem aktiivsed ning aktiivsus kasvab kuni ajani, mil koolijuhil on umbes 30 aastat staaži, ning hakkab seejärel uuesti langema. Pittaway ja Hannon (2008) on arvanud, et suhted väliste huvirühmadega on kooli jaoks strateegilise tähtsusega ning nende korraldamisel on koolijuhtidel oma osa. Meie uurimistulemused näitavad, et väiksema kogemusega koolijuhid on huvirühmadega suhtlemisel vähem aktiivsed, kuigi nad võivad kasutada ettevõtetega suhtlemiseks ka muid kanaleid ja viise. Samas võivad need uurimistulemused viidata sellele, et koolijuhid hakkavad väliste huvirühmadega suhtlemise strateegiat rakendama alles pärast mõneaastast töötamist.

Meie kolmas väide oli selline: „ettevõtlusega seotud koolitusel osalemine mõjutab koolijuhti väliseid huvirühmi ettevõtlusõppesse rohkem kaasama“. Koolijuhtide koolitamine ettevõtlusõppe valdkonnas on tõhus vahend, mis aitab kaasata väliseid huvirühmi. Seega leidis meie väide kinnitust. Huvitav on see, et peaaegu kaks korda suurema koostöövalmidusega olid need koolijuhid, kes olid osalenud vähemalt mõnel koolitusel, võrreldes mitte ühelgi koolitusel osalenud koolijuhtidega.

Kokkuvõttes täiendab see uurimus kirjandust ettevõtlusõppe kohta, pakkudes uut arusaama, kas ja kuidas mõjutab koolijuhtide taust väliste huvirühmade kaasamist kooli ettevõtlusõppe arendamisse. Esiteks osutavad uurimistulemused, et koolijuhtide varasem ettevõtlustaust ei mõjuta nende tegevust väliste huvirühmade kasutamisel. Teiseks ei mõjuta seda ka koolijuhtide staaž. Kolmandaks, ettevõtlusõpet käsitlev koolitus näib olevat väga tõhus viis edendada väliste huvirühmade kaasamist. Lisaks näitavad uurimistulemused, et väliste huvirühmade kaasamine ei sõltu koolijuhi soost ning et mida suurem on kool, seda rohkem kasutab selle juht meie uurimuses vaadeldud partnereid.

Esitatud uurimistulemused tekitavad mitmeid küsimusi. Näiteks kui ettevõtted ja välised huvirühmad täidavad ettevõtlushariduse arendamisel põhirolli (Jones \& Iredale, 2010; Solomon, 2007), siis kuidas anda koolijuhtidele võimalus nendega ühendust võtta? Uurimistulemused näitavad, et tavaliselt kasutavad koolijuhid ühte välist huvirühma. Millised on siis parimad kanalid suhete arendamiseks ja kuidas loodud suhteid edasi arendada? Kes peaks initsiatiivi näitama? Või on nõudlus ja pakkumine juba tasakaalus? Samas ei ilmne meie uurimistulemustest, kuidas koolijuhid väliseid huvirühmi kaasavad. Seega võib ka vaid ühel huvirühmal olla väga mõjus roll kooli ettevõtlusõppes, kuid see võib ka täielikult puududa. Ja viimane küsimus: kui mitut välist huvirühma tuleks ideaalis kasutada ning mis rollis oleksid koolijuhid ja õpetajad kõige kasulikumad? 
Kuna koostöö nõuab motiveeritust ja võimekust mõlemalt osaliselt, tõstatab meie uurimus küsimuse, mis motiveerib huvirühmi ja milline on nende suutlikkus teha koolidega koostööd. See oleks väga huvitav uurimisteema ja tegelikult on mõned uurimused selle kohta ka juba olemas (nt Sommarström et al., 2017). Samas näitab meie uurimus, et kõiki huvirühmi motiveerib koostöö koolidega, sest see ongi nende tegelik ülesanne. Võibolla oleks motivatsioon teistsugune, kui koostööd tehtaks eraettevõtetega.

Mõnes uurimuses (Birdthistle et al., 2007; Gibb, 2011) on rõhutatud vajadust suurendada ettevõtlusõppesse suunatavaid ressursse. See on mõistetav, kuid samas tekitab küsimusi praeguse uurimistöö tulemusena selgunud asjaolu, et vaadeldud organisatsioonid tegutsevad vabatahtlikkuse alusel ja pakuvad tasuta materjale, kuid neid kasutatakse siiski nii vähe. Muidugi võiks küsida, kas asi on pakkumises ja nõudluses või ei tea asjaosalised, kuidas oleks kõige parem koostööd teha. Varasemate uurimuste (Dickson et al., 2008; Jones \& Iredale, 2010) põhjal tundub siiski, et seda oskust tasuks arendada.

Siinse uurimuse eesmärk ei olnud leida seoseid koolijuhtide ettevõtlustausta ja mitmesuguste ärikontaktide haridusliku kasutamise vahel. Samas oleme arvamusel, et koolijuhtide ettevõtlustausta osakaal ja mõju ettevõtlusõppes vajaks edasist uurimist. Järeldused, mis tehti koolijuhtide töökogemuse ja ettevõtlusega seotud koolituste olulisuse kohta, võivad osutuda kasulikuks näiteks uute koolijuhtide palkamisel. Uurimistulemused viitavad, et koolijuhtide osalemine ettevõtlusõppealastel koolitustel on tähtis, ja see on uurimuse väga praktiline järeldus.

Näib, et koolijuhtide ettevõtlusõppealase koolituse kaudu on võimalik väga tõhusalt edendada huvirühmade kaasamist. Koolijuhtidele pakutakse mitmesuguseid koolitusi, näiteks juhtimise, personalijuhtimise, administratiivtöö ja majanduse valdkonnas. Need teadmised on nende töös väga olulised. Samas on spetsiaalselt koolijuhtidele mõeldud ettevõtluskoolitusi väga vähe. Seega soovitame pakkuda rohkem üksnes koolijuhtidele mõeldud ettevõtluskoolitusi, mis vastaksid nende vajadustele.

Et mõista, milline on koolijuhtide osa koolisisese ettevõtlusõppe juhtimises, suunamises ja toetamises, on tarvis rohkem uurimusi. Praeguses uurimuses keskendusime üksnes sellele, kuidas koolijuhid kaasavad väliseid huvirühmi, kuid ei käsitlenud muid ettevõtlusõppega seotud olulisi aspekte. Näiteks jäi uurimuse fookusest välja küsimus, mis koostööd on koolijuhid huvirühmadega teinud, samuti ei uurinud me õpetajate arvamusi. Huvitav oleks vaadelda ka koolikultuuri ja seda, milline on koolijuhtide roll kooli juhtimisel või arendamisel seoses ettevõtlusõppele seatud eesmärkidega.

Nii nagu iga uurimus, sisaldab ka meie oma mõningaid piiranguid. Töös uurisime vaid tasuta tegutsevaid väliseid huvirühmi. Tulemused oleksid võinud 
olla teistsugused, kui kaasatud oleksid olnud ka eraettevõtted. Meile teadaolevalt on selliseid eraettevõtteid, kes pakuvad koolidele ettevõtlusõppega seotud teenuseid, siiski üsna vähe. Lisaks on koolide eelarved üsna piiratud. Seetõttu kasutatakse äriettevõtete teenuseid koolides üpris harva ja meie lähenemisviis on seega asjakohane. Pealegi koguti andmeid ainult ühes riigis ja seetõttu ei saa selle põhjal teha rahvusvahelise ulatusega üldistusi. Andmeid koguti veebi kaudu ja koolijuhid vastasid küsimustikule vabatahtlikult. Olgugi et olulised otsustajad õhutasid koolijuhte vastama, võib siiski siinses uurimuses olla enam esindatud ettevõtlusõppe suhtes positiivsemalt häälestatud koolijuhid. Sellest hoolimata loodame, et uurimistulemused pakuvad rahvusvahelist huvi, sest koolijuhtide rolli ettevõtlusõppes on väga vähe uuritud ning me soovime juhtida tähelepanu Soome panusele ettevõtlusõppe kinnistamisel koolides ja sellega seotud pikkadele traditsioonidele Euroopas.

\section{Kasutatud kirjandus}

Ballou, D., \& Podgursky, M. (1995). Recruiting smarter teachers. The Journal of Human Resources, 30(2), 326-338. https://doi.org/10.2307/146122

Bell, J., Callaghan, I., Demick, D., \& Scharf, F. (2004). Internationalising entrepreneurship education. Journal of International Entrepreneurship, 2(1-2), 109-124. https://doi.org/10.1023/B:JIEN.0000026908.35126.15

Bennett, R. (2006). Business lecturers' perceptions of the nature of entrepreneurship. International Journal of Entrepreneurial Behavior \& Research, 12(3), 165-188. https://doi.org/10.1108/13552550610667440

Birdthistle, N., Hynes, B., \& Fleming, P. (2007). Enterprise education programmes in secondary schools in Ireland. Education + Training, 49(4), 265-276. https://doi.org/10.1108/00400910710754426

Cooper, S., Bottomley, C., \& Gordon, J. (2004). Stepping out of the classroom and up the ladder of learning: An experiential learning approach to entrepreneurship education. Industry and Higher Education, 18(1), 11-22. https://doi.org/10.5367/000000004773040924

Deakins, D., Glancey, K., Menter, I., \& Wyper, J. (2005). Enterprise education: The role of head teachers. The International Entrepreneurship and Management Journal, 1(2), 241-263. https://doi.org/10.1007/s11365-005-1131-9

Dickson, P. H., Solomon, G. T., \& Weaver, K. M. (2008). Entrepreneurial selection and success: Does education matter? Journal of Small Business and Enterprise Development, 15(2), 239-258. https://doi.org/10.1108/14626000810871655

Ememe, O. N., Ezeh, S. C., \& Ekemezie, C. A. (2013). The role of head-teacher in the development of entrepreneurship education in primary schools. Academic Research International, 4(1), 242-249.

European Commission (2013). Entrepreneurship 2020 Action Plan. COM (2012) 795 Final. Brussels. 
European Parliament and the Council (2006). Recommendation of the European Parliament and of the Council of 18 December 2006 on key competences for lifelong learning. Official Journal of the European Union, L394/310.

Eurydice (2016). Entrepreneurship education at school in Europe. Eurydice Report. Luxembourg: Publications Office of the European Union.

Gibb, A. (2011). Concepts into practice: Meeting the challenge of development of entrepreneurship educators around an innovative paradigm: The case of the International Entrepreneurship Educators' Programme (IEEP). International Journal of Entrepreneurial Behaviour \& Research, 17(2), 146-165. https://doi.org/10.1108/13552551111114914

Hämäläinen, M., Ruskovaara, E., \& Pihkala, T. (2018). Principals promoting entrepreneurship education: The relationships between development activities and school practices. Journal of Entrepreneurship Education, 21(2), 1-19. Retrieved from https://www.abacademies.org/abstract/principals-promoting-entrepreneurshipeducation-the-relationships-between-development-activities-and-schoolpractises-7127.html.

Jones, B., \& Iredale, N. (2010). Enterprise education as pedagogy. Education + Training, 52(1), 7-19. https://doi.org/10.1108/00400911011017654

Matlay, H. (2009). Entrepreneurship education in the UK: A critical analysis of stakeholder involvement and expectations. Journal of Small Business and Enterprise Development, 16(2), 355-368. https://doi.org/10.1108/14626000910956100

Ministry of Education (2009). Guidelines for entrepreneurship education. Publication of the Ministry of Education. Finland 2009:9. Helsinki: University Print.

Opetushallitus (2017). Opettajat ja rehtorit Suomessa 2016. In T. Kumpulainen (Ed.), Raportit ja selvitykset 2017:2. Juvenes Print - Suomen Yliopistopaino Oy.

Pittaway, L., \& Hannon, P. (2008). Institutional strategies for developing enterprise education: A review of some concepts and models. Journal of Small Business and Enterprise Development, 15(1), 202-226. https://doi.org/10.1108/14626000810850937

Ruskovaara, E., Hämäläinen, M., \& Pihkala, T. (2016). HEAD teachers managing entrepreneurship education - Empirical evidence from general education. Teaching and Teacher Education, 55, 155-164. https://doi.org/10.1016/j.tate.2016.01.004

Ruskovaara, E., \& Pihkala, T. (2013). Teachers implementing entrepreneurship education: Classroom practices. Education + Training, 55(2), 204-216. https://doi.org/10.1108/00400911311304832

Ruskovaara, E., \& Pihkala, T. (2015). Entrepreneurship education in schools: Empirical evidence on the teacher's role. The Journal of Educational Research, 108(3), 236-249. https://doi.org/10.1080/00220671.2013.878301

Ruskovaara, E., Pihkala, T., Seikkula-Leino, J., \& Järvinen, M. R. (2015a). Broadening the resource base for entrepreneurship education through teachers' networking activities. Teaching and Teacher Education, 47, 62-70.

https://doi.org/10.1016/j.tate.2014.12.008 
Ruskovaara, E., Pihkala, T., Seikkula-Leino, J., \& Rytkölä, T. (2015b). Creating a measurement tool for entrepreneurship education: A participatory development approach. In A. Fayolle, P. Kyrö, \& F. Liñán (Eds.), Developing, shaping and growing entrepreneurship (pp. 40-57). Cheltenham: Edward Elgar Publishing. https://doi.org/10.4337/9781784713584.00009

Seikkula-Leino, J. (2007). Opetussuunnitelmauudistus ja yrittäjyyskasvatuksen toteuttaminen. Opetus-ja kulttuuriministeriö.

Solomon, G. (2007). An examination of entrepreneurship education in the United States. Journal of Small Business and Enterprise Development, 14(2), 168-182. https://doi.org/10.1108/14626000710746637

Sommarström, K., Ruskovaara, E., \& Pihkala, T. (2017). Company visits as an opportunity for entrepreneurial learning. Journal for International Business and Entrepreneurship Development, 10(3), 298-315. https://doi.org/10.1504/JIBED.2017.085505

Sullivan, R. (2000). Entrepreneurial learning and mentoring. International Journal of Entrepreneurial Behavior \& Research, 6(3), 160-175.

https://doi.org/10.1108/13552550010346587 